\title{
Development, Implementation, and Assessment of a Genetics Curriculum Across Institutions
}

\author{
Sarah Dotters-Katz, MD ${ }^{1}$ Ginger Hocutt, $\mathrm{MS}^{1}$ \\ Laurie Demmer, $\mathrm{MD}^{3,4}$ Neeta Vora, $\mathrm{MD}^{1}$ \\ ${ }^{1}$ Division of Maternal-Fetal Medicine, University of North Carolina at \\ Chapel Hill, Chapel Hill, North Carolina \\ ${ }^{2}$ Ambry Genetics, formerly of Division of Maternal-Fetal Medicine, \\ University of North Carolina at Chapel Hill, Chapel Hill, North Carolina \\ ${ }^{3}$ Division of Maternal-Fetal Medicine, Tufts University, Boston, \\ Massachusetts \\ ${ }^{4}$ Division of Maternal-Fetal Medicine, Carolinas Medical Center, \\ Charlotte, North Carolina
}

Am J Perinatol Rep 2016;6:e372-e377.
Address for correspondence Sarah Dotters-Katz, MD, Division of Maternal-Fetal Medicine, University of North Carolina at Chapel Hill, 3010 Old Clinic Building, CB \# 7516, Chapel Hill, NC 27599-7516 (e-mail: sarahdk@med.unc.edu).

\begin{abstract}
Keywords

- genetics

- curriculum

- resident education

- prenatal diagnosis
\end{abstract}

Objective Many residency programs offer limited exposure and minimal didactic time genetics, despite its frequent use in obstetrics and gynecology. The objective of this study was to develop, pilot, and assess a three-module women's health genetics curriculum for residents that was easily transferable between institutions.

Methods An interactive three-module genetics curriculum covering basic principles, prenatal screening/diagnosis, and cancer genetics was developed. A pre- and posttests were used to assess improvement in knowledge. Subjective feedback was obtained to assess curricular satisfaction. The data were analyzed with descriptive statistics.

Results The curriculum was administered at two institutions. Forty-eight residents attended $\geq 1$ session. Twenty completed the pretest, and 23 completed the posttest. At the first institution, using audience response system, the percentage correct per question increased on 10/14 questions between pre- and posttests. All students felt the curriculum was useful and would strongly recommend to other residents. At the second institution, pre/posttests were distributed on paper. Mean scores significantly improved between pre- and posttests $(p=0.007)$. On the pretest, no residents scored $>70 \%$. However, $8 / 13$ scored $>70 \%$ on the posttest $(p=0.002)$. Instructors at both institutions described the curriculum as easy to use/implement.

Conclusion This three-module workshop on women's health genetics was easily implemented across institutions and led to increased knowledge.
Genetics and genomics play a critical role in obstetrics and gynecology (Ob/Gyn). The American College of Obstetrics and Gynecology recommends that aneuploidy screening or diagnostic testing should be made available to every woman in early pregnancy. ${ }^{1}$ An increasing number of genetic tests are also available for gynecologic malignancies associated with familial cancer syndromes such as Lynch syndrome (hereditary nonpolyposis colon cancer)

received

August 18, 2016 accepted after revision September 17, 2016
DOI http://dx.doi.org/ $10.1055 / \mathrm{s}-0036-1593831$. ISSN 2157-6998. or hereditary breast and ovarian cancer syndromes (BRCA) genes. Decisions regarding how to screen for specific cancer syndromes and inherited disorders often fall to women's health care providers. Specific challenges related to genetic testing include providing adequate pre- and posttests counseling, interpreting variants of uncertain clinical significance, and making clinical decisions regarding management of care based on results of testing.
Copyright $\odot 2016$ by Thieme Medical Publishers, Inc., 333 Seventh Avenue, New York, NY 10001, USA. Tel: +1(212) 584-4662.
License terms

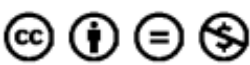


Ob/Gyn providers are faced with both patient discussions and medical decisions related to genetics/genomics daily. Many new screening and molecular tests that take advantage of next-generation sequencing technologies emerge each year. Laboratory representatives marketing their testing products frequently approach providers and patients are exposed to information regarding these tests via the Internet and social media. As a result, genetics and genomics are being integrated into clinical care at a rapid pace. Thus, it is essential that individuals caring for women at any stage of life are well educated regarding genetics and genetic testing.

Unfortunately, current literature suggests that most providers do not feel comfortable with genetics or discussing genetic testing with patients. ${ }^{2-4}$ This extends to physicians in training as well. ${ }^{3}$ Despite this, there are milestones from the Accreditation Council for Graduate Medical Education (ACGME) and objectives from the Council on Resident Education for Obstetrics and Gynecology (CREOG) relating specifically to this subset of knowledge. ${ }^{5,6}$ Thus, our objective was to develop a simple and effective women's health genetics curriculum, which can be easily deployed across institutions meeting both ACGME milestones and CREOG objectives. Our hypothesis was that this intervention would result in improved resident knowledge regarding topics in women's health genetics.

\section{Methods}

A three-module women's health-oriented genetics curriculum was developed based on a perceived gap in Ob/Gyn resident knowledge regarding genetics and addressing both ACGME milestones and CREOG objectives. Modules were created in PowerPoint and designed to be interactive. These modules were developed by a maternal-fetal medicine (MFM) geneticist, a pediatric geneticist, and two genetic counselors (one with a specialty in reproductive genetics and one with a specialty in cancer genetics). The modules were then reviewed by two additional genetic counselors and a MFM specialist. Content was created for the purpose of being adaptable to a variety of audiences, time frames, and venues. The above instructors also created a knowledge assessment to be given as a pre- and posttests (-Appendix A). The same individuals who reviewed the modules also evaluated this assessment for clarity and content.

The first module, designed to be given by either a geneticist or genetic counselor, focused on basic genetics concepts, including the structure and function of chromosomes, common genetic condition, translocations, molecular genetics, and available cytogenetic and molecular tests. The second module, designed to be taught by either an MFM physician or MFM geneticist, focused on prenatal diagnosis and screening. Finally, the third module, designed to be given by a cancer genetics professional, included discussion of the genetics of cancer, common familial cancer syndromes, and indications for testing. A full outline of the key concepts and associated milestones are listed in - Table 1. The modules were piloted for Ob/Gyn residents as they are often the health care professional who provides the most genetics education in women's health. However, the modules were designed to also

Table 1 Genetics concepts described and discussed during each session of the curriculum with the aligned ACGME milestones and CREOG objectives ${ }^{5,6}$

\begin{tabular}{|c|c|c|c|}
\hline & Session 1 (basic genetics) $^{a, b, c, d, e, f}$ & Session 2 (prenatal diagnosis) ${ }^{b, c, d, g}$ & Session 3 (cancer genetics) $^{a, b, c, f, h}$ \\
\hline $\begin{array}{l}\text { Key } \\
\text { themes }\end{array}$ & $\begin{array}{l}\text { Basic structure of DNA } \\
\text { Meiosis } \\
\text { Pedigree } \\
\text { Trinucleotide repeat } \\
\text { disorders } \\
\text { Translocations } \\
\text { Common genetic tests } \\
\text { (karyotype, microarray, } \\
\text { molecular testing) } \\
\text { Imprinting disorders } \\
\text { Multifactorial inheritance }\end{array}$ & $\begin{array}{l}\text { Screening vs. diagnostic tests } \\
\text { Serum screening } \\
\text { Cell-free DNA screening } \\
\text { Sensitivity, specificity, and } \\
\text { positive predictive value } \\
\text { Ultrasounds screening } \\
\text { Common aneuploidies } \\
\text { Carrier screening } \\
\text { Cystic fibrosis } \\
\text { Jewish specific conditions } \\
\text { Sickle cell disease Hemoglobinopathies } \\
\text { Fragile X syndrome } \\
\text { Counsel patients about risks and } \\
\text { benefits of various diagnostic tests } \\
\text { Chorionic villus sampling, } \\
\text { Amniocentesis } \\
\text { Preimplantation genetic diagnosis }\end{array}$ & $\begin{array}{l}\text { Genetic basis for hereditary } \\
\text { cancer syndromes } \\
\text { Breast cancer syndromes } \\
\text { Colon cancer (Lynch, juvenile } \\
\text { polyposis syndrome, Cowden } \\
\text { syndrome, Peutz-Jeghers } \\
\text { syndrome) } \\
\text { Ovarian cancer syndromes } \\
\text { Endometrial cancer syndromes }\end{array}$ \\
\hline
\end{tabular}

Abbreviations: ACGME, Accreditation Council for Graduate Medical Education; CREOG, Council on Resident Education for Obstetrics and Gynecology. Note: ACGME milestones ${ }^{\mathrm{a}, \mathrm{b}, \mathrm{c}, \mathrm{d}}$ and CREOG genomics objectives $\mathrm{s}^{\mathrm{e}, \mathrm{f}, \mathrm{g}, \mathrm{h}}$ were addressed by the curriculum.

${ }^{\mathrm{a}}$ Care of the patient with nonreproductive medical disorders-patient care.

${ }^{b}$ Health care maintenance and disease prevention-medical knowledge.

${ }^{\mathrm{c}}$ Cost-effective care and patient advocacy-systems-based practice.

${ }^{\mathrm{d}}$ Antepartum care and complications of pregnancy-patient care.

${ }^{\mathrm{e}}$ Core competencies.

fPrimary and preventative ambulatory health.

${ }^{\text {gObstetrics. }}$

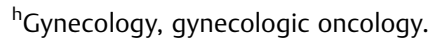


be usable for family medicine or other health care professionals who provide care to women. Although each module can be presented individually, they were designed to build on each other. At the first institution, an audience response system was used during the lectures to increase interactive audience participation. After completing the sessions, a series of qualitative satisfaction questions to assess satisfaction with the curriculum were asked anonymously.

At the second institution, the workshops were given in a series of three 1-hour sessions during protected resident didactic time. A paper version of the pretest was given before the first module and the posttest was administered following completion of the third module.

\section{Results}

Data are being presented per institution, as pre- and posttests were administered and assessed differently. At the first institution, a total of 17/20 residents attended at least one optional module. An audience response system was used to tally responses during the lectures to increase participation and engage the residents. The overall percentage of residents selecting the correct response on each question increased on 10 out of 14 questions between the pre- and posttests. The questions that had the largest percentage increases are displayed in - Table 2. Among these questions, six questions had more than $70 \%$ of residents responded correctly on posttest, compared with five on the pretest. Finally, there were two questions on the pretest that no student answered correctly; 20 and 30\% of students answered these two questions correctly, respectively, on the posttest.
Table 3 Subjective feedback on the curriculum from the first institution $^{\mathrm{a}}$

\begin{tabular}{|l|l|}
\hline & $\begin{array}{l}\text { Mean score } \\
( \pm \mathrm{SD})\end{array}$ \\
\hline $\begin{array}{l}\text { This curriculum was helpful in increasing } \\
\text { knowledge of genetics }\end{array}$ & $3.8 \pm 0.4$ \\
\hline The presentation quality was good & $3.8 \pm 0.4$ \\
\hline $\begin{array}{l}\text { I would recommend this series } \\
\text { to other residents }\end{array}$ & $4.0 \pm 0$ \\
\hline $\begin{array}{l}\text { The audience response system was } \\
\text { engaging way to learn }\end{array}$ & $4.0 \pm 0$ \\
\hline
\end{tabular}

Abbreviation: SD, standard deviation.

Note: Scale of 1 to 4 , with $4=$ strongly agree, $3=$ somewhat agree, $2=$ disagree somewhat, and $1=$ strongly disagree.

${ }^{a}$ Completed by 10 residents.

Subjective feedback on the modules obtained after the posttest was overwhelmingly positive (-Table 3 ). Eighty percent of residents felt all three modules were very helpful, while the other $20 \%$ found them moderately helpful. The interactive style and presentation were rated as $4 / 4$ by $80 \%$ of respondents and $3 / 4$ by $20 \%$ of respondents. All participants stated they would strongly recommend this curriculum to other $\mathrm{Ob} /$ Gyn residents.

At the second institution, all of the 28 residents attended at least one session. However, of a possible 20 available, 13 residents were at session 1,14 at session 2 , and 13 at session 3 . The pre- and posttests were administered and answered on paper. The median score increased significantly from $8 / 14$

Table 2 Questions where the total percentage of respondents answering correctly increased most dramatically

\begin{tabular}{|c|c|c|}
\hline Question & Responses & $\begin{array}{l}\text { Percentage of correct increase } \\
\text { between pre- and posttests }{ }^{\mathrm{a}}\end{array}$ \\
\hline $\begin{array}{l}\text { A couple's first child is born with unilateral cleft lip } \\
\text { and palate. The family and pregnancy history are } \\
\text { otherwise unremarkable. Thorough dysmorphol- } \\
\text { ogy examination is otherwise negative. Karyotype } \\
\text { and microarray analysis are normal. Which of the } \\
\text { following would be an appropriate recurrence risk } \\
\text { to quote this couple? }\end{array}$ & $\begin{array}{l}\text { a. }<1 \% \\
\text { b. } 3 \% \\
\text { c. } 10 \% \text { b } \\
\text { d. } 25 \% \\
\text { e. } 50 \%\end{array}$ & $30 \%$ \\
\hline $\begin{array}{l}\text { In comparison with other individuals of Northern } \\
\text { European ancestry, all of the following autosomal } \\
\text { recessive genetic disorders have an increased fre- } \\
\text { quency in the Ashkenazi Jewish population except: }\end{array}$ & $\begin{array}{l}\text { a. Bloom syndrome } \\
\text { b. Canavan syndrome } \\
\text { c. Cystic fibrosis } \\
\text { d. Familial dysautonomia } \\
\text { e. Type } 1 \text { Gaucher disease }\end{array}$ & $24 \%$ \\
\hline $\begin{array}{l}\text { Which of the following assisted reproduction } \\
\text { techniques are associated with a } 1 \% \text { increase in the } \\
\text { rate of sex chromosomal aneuploidy in the fetus? }\end{array}$ & $\begin{array}{l}\text { a. Embryo freezing } \\
\text { b. Preimplantation genetic diagnosis } \\
\text { c. ICSI }{ }^{\mathrm{b}} \\
\text { d. IUI }\end{array}$ & $14 \%$ \\
\hline $\begin{array}{l}\text { You are called to see a newborn infant with mi- } \\
\text { crocephaly, cleft lip and palate, polydactyly, and } \\
\text { complex congenital heart disease. What is the most } \\
\text { likely diagnosis? }\end{array}$ & $\begin{array}{l}\text { a. } 45 X \\
\text { b. } 47, X X,+18 \\
\text { c. } 46, X Y, \operatorname{der}(13 ; 14)(q 10 ; q 10),+13^{b} \\
\text { d. } 47, X X,+21\end{array}$ & $20 \%$ \\
\hline
\end{tabular}

Abbreviations: ICSI, intracytoplasmic sperm injection; IUI, intrauterine insemination.

aThis value was obtained by taking the percentage of students who answered correctly on the pretest and subtracting this from the percentage of students who answered correctly on the posttest.

benotes correct response. 
Table 4 Results from the pre- and posttests for residents at the second institution

\begin{tabular}{|l|l|l|l|}
\hline & $\begin{array}{l}\text { Pretest } \\
\boldsymbol{n}=\mathbf{1 3}\end{array}$ & $\begin{array}{l}\text { Posttest } \\
\boldsymbol{n}=\mathbf{1 3}\end{array}$ & -Value \\
\hline $\begin{array}{l}\text { Median score for all } \\
\text { residents (IQR) }\end{array}$ & $8(6,8)$ & $10(9,12)$ & 0.0071 \\
\hline $\begin{array}{l}\text { Median score for } \\
\text { interns (IQR) }\end{array}$ & $6(5,8)$ & $12(12,12.5)$ & 0.011 \\
\hline $\begin{array}{l}\text { Individuals with } \\
\text { passing score (\%) }\end{array}$ & $0(0)$ & $8(62)$ & 0.002 \\
\hline
\end{tabular}

Abbreviation: IQR, interquartile range.

Note: $n=$ number of residents who took the test.

apre- and posttests included a total of 14 questions.

${ }^{\mathrm{b}}$ Passing score defined as $>70 \%$.

(interquartile range [IQR]: 6, 8) on the pretest to 10/14(IQR: 9, 12 ) on the posttest ( $p=0.0071$ ) ( - Table 4 ). When assessing scores for the postgraduate year 1 class, there was an overall improvement from $6 / 14$ (IQR: 5,8 ) on the pretest to $12 / 14$ (IQR $12,12.5)$ on the posttest $(p=0.011)$. Although no residents achieved a passing score (70\%) on the pretest, 8 of 13 achieved a passing score on the posttest $(p=0.002)$.

Instructors at both institutions described the curriculum as, "easy to implement." Those from the second institution described the format as "easily adaptable to 1 hour time slot" and "an effective way to engage the residents.

\section{Conclusion}

We demonstrated that a three-module women's health genetics curriculum is effective at increasing resident knowledge and that this curriculum is easily transferrable between institutions without losing efficacy. We also demonstrated that a curriculum could be designed to meet both ACGME and CREOG objectives.

Despite the frequency with which genetics is utilized in women's health, there is a paucity of data regarding genetics education, though a clear need has been demonstrated. Physician preparedness regarding genetic testing and genetic counseling has been shown by many authors to be poor. ${ }^{3}$ Even among $\mathrm{Ob} / \mathrm{Gyn}$ residents, 76\% expressed a desire and need for education regarding hereditary cancer and genetic testing. ${ }^{7}$ Among residents entering a genetics-specific residency after completion of a primary residency, ratings by program directors on a scale of 1 to 10 , with 1 being minimal, averaged $2.6 / 10$ in prenatal genetics knowledge and 2.8/10 in cancer genetics knowledge. ${ }^{8}$ These data highlight the need for increasing genetics education among providers responsible for sending genetic tests.

Over 10 years ago, Macri et al described a comprehensive genetics curriculum for $\mathrm{Ob} / \mathrm{Gyn}$ residents that included two 3-hour didactic sessions and one 3-hour session at a simulation center. ${ }^{9}$ After completing this curriculum, nearly $90 \%$ of residents showed improved knowledge, and felt subjectively more confident with material relating to genetics. In this new era of genomic medicine, it is even more critical to explore ways of increasing trainee's knowledge in genetics and genomics. Though residents demonstrated significantly increased knowledge with this approach, not all Ob/Gyn residency programs have the time or the resources to implement such a comprehensive curriculum. Trainees in other specialties that provide prenatal care and women's health care, such as family medicine residents and internal medicine residents, are even less likely to have the time and resources for an intensive curriculum. The curriculum presented here is easily transferrable between institutions, and can be adjusted or expanded based on the time available. It is also designed to be taught a variety of providers to increase adaptability.

Genetics education is part of the ACGME milestones for Ob/Gyn, family medicine, and internal medicine. More importantly, providers in women's health care are exposed to genetics and genetic testing in daily practice. Thus, the development and implementation of genetics curricula are critical to ensure that residents who provide care in women's health emerge from training equipped to provide comprehensive care related to women's reproductive genetics.

\section{Prior Presentation}

These data were presented at the American Society of Human Genetics (San Diego, CA, 2014) and the American College of Medical Genetics (Tampa, FL, 2009).

\section{Source}

This study was performed at the University of North Carolina at Chapel Hill and at Tufts Medical Center.

\section{Conflict of Interest}

The authors report no conflict of interest.

\section{Acknowledgment \\ None.}

\section{References}

1 Practice Bulletin No. 163: screening for fetal aneuploidy. Obstet Gynecol 2016;127(5):e123-e137

2 Brierley KL, Blouch E, Cogswell W, et al. Adverse events in cancer genetic testing: medical, ethical, legal, and financial implications. Cancer J 2012;18(4):303-309

3 Selkirk CG, Weissman SM, Anderson A, Hulick PJ. Physicians' preparedness for integration of genomic and pharmacogenetic testing into practice within a major healthcare system. Genet Test Mol Biomarkers 2013;17(3):219-225

4 Plon SE, Cooper HP, Parks B, et al. Genetic testing and cancer risk management recommendations by physicians for at-risk relatives. Genet Med 2011;13(2):148-154

5 CREOG Educational Objectives: A Core Curriculum in Obstetrics and Gynecology, 10th ed. Washington, DC: American College of Obstetricians and Gynecologists; 2013

6 The obstetrics and gynecology milestone project. J Grad Med Educ 2014;6(1, Suppl 1):129-143

7 Ready KJ, Daniels MS, Sun CC, Peterson SK, Northrup H, Lu KH. Obstetrics/gynecology residents' knowledge of hereditary breast 
and ovarian cancer and Lynch syndrome. J Cancer Educ 2010; 25(3):401-404

8 Bupp CP, Demmer LA, Saul RA. Surveying the current landscape of clinical genetics residency training. Genet Med 2015;17(5): 386-390

\section{Appendix A: Genetics Knowledge Assessment}

1. Colon cancer is the most common malignancy seen in families with hereditary nonpolyposis colon cancer or Lynch syndrome. What is the second most common malignancy?
(a) Breast cancer
(b) Endometrial cancer
(c) Ovarian cancer
(d) Pancreatic cancer
(e) Stomach cancer

2. Bonnie and Clyde are referred for preconception genetic counseling. They met a local benefit for cystic fibrosis. Clyde is healthy but has a sister with cystic fibrosis (CF). Bonnie has $\mathrm{CF}$. What is their risk to have a child with CF?
(a) $25 \%$
(b) $33 \%$
(c) $50 \%$
(d) $67 \%$
(e) $100 \%$

3. In comparison with other individuals of Northern European ancestry, all of the following autosomal recessive genetic disorders have an increased frequency in the Ashkenazi Jewish population except:
(a) Bloom syndrome
(b) Canavan disease
(c) Cystic fibrosis
(d) Familial dysautonomia
(e) Type I Gaucher disease

4. Which of the following assisted reproduction techniques are associated with a $1 \%$ increase in the rate of sex chromosomal aneuploidy in the fetus?
(a) Embryo freezing
(b) Preimplantation genetic diagnosis
(c) Intracytoplasmic sperm injection
(d) Intrauterine insemination

5. A newborn male with hypotonia, failure-to-thrive, and undescended tested is diagnosed with Prader-Willi syndrome. The most likely etiology for this condition is:
(a) Deletion on the paternal chromosome 15
(b) Gonadal mosaicism
(c) Deletion on the maternal chromosome 15
(d) Somatic mosaicism
(e) Trinucleotide repeat expansion

6. Mr. John Doe is referred for preconception genetic counseling regarding a family history of fragile $\mathrm{X}$ syndrome. Genetic testing is performed, and John is found to carry 80 cytosine guanine guanine (CGG) trinucleotide repeats. What can you tell John about the risk to his future offspring regarding fragile $\mathrm{X}$ ?
(a) All of his sons will be affected with fragile $X$

9 Macri CJ, Gaba ND, Sitzer LM, Freese L, Bathgate SL, Larsen JW Jr. Implementation and evaluation of a genetics curriculum to improve obstetrician-gynecologist residents' knowledge and skills in genetic diagnosis and counseling. Am J Obstet Gynecol 2005; 193(5):1794-1797

(b) All of his sons will carry a premutation

(c) All of his daughters will be affected with fragile X

(d) All of his daughters will carry a premutation

7. A couple presents for prenatal genetic counseling following the identification of aortic coarctation on routine ultrasound evaluation. Amniocentesis is performed. The results are consistent with an abnormal female chromosome complement $(45, \mathrm{X})$. Which of the following would you discuss as being a likely outcome for this couple's daughter?
(a) Normal intelligence
(b) Ovarian failure
(c) Short stature
(d) All of the above
(e) None of the above

8. You are called to see a neonate with microcephaly, cleft lip and palate, postaxial polydactyly, and a complex congenital heart defect. Of the following, what is the most likely karyotype of this neonate?
(a) $45, X$
(b) $45, X Y, r o b(13 ; 14)(q 10 ; q 10)$
(c) $46, X Y, \operatorname{rob}(13 ; 14)(q 10 ; q 10),+13$
(d) $47, X X,+21$
(e) $47, \mathrm{XXX}$

9. Which of the following structural chromosome rearrangements carries the highest risk of producing a viable imbalance (i.e., a living offspring with abnormalities)?
(a) Robertsonian translocation
(b) Pericentric inversion
(c) Paracentric inversion
(d) Intrachromosomal insertion
(e) Interchromosomal insertion

10. A couple's first child is born with unilateral cleft lip and palate. The family and pregnancy history are otherwise unremarkable. Thorough dysmorphology examination is otherwise negative. Karyotype and microarray analysis are normal. Which of the following would be an appropriate recurrence risk to quote this couple?
(a) $<1 \%$
(b) $3 \%$
(c) $10 \%$
(d) $25 \%$
(e) $50 \%$

11. You are called to see a neonate with growth retardation, microcephaly, micrognathia, low set ears, overlapping fingers, and rocker bottom feet. Which of the following is the most likely diagnosis?
(a) Trisomy 13
(b) Trisomy 18
(c) Trisomy 21
(d) Turner syndrome
(e) Klinefelter syndrome 
12. Which pattern of inheritance is suggested by this pedigree?

Answers:

1. b

2. b

3. c

(a) Autosomal dominant

4. $\mathrm{c}$

(b) Autosomal recessive

5. a

(c) X-linked recessive

6. d

(d) None of the above

7. d

8. c

13. Advanced paternal age is considered to be a risk factor in which type of Mendelian disorder?
(a) Autosomal dominant
10. b
(b) Autosomal recessive
11. b
(c) $\mathrm{X}$-linked recessive
12. c
(d) Y-linked
13. a

9. e 